Article

\title{
Fashion Everydayness as a Cultural Revolution in Social Media Platforms-Focus on Fashion Instagrammers
}

\author{
Sungeun Suh $\mathbb{1}$ \\ Fashion Design Major, College of Arts, Gachon University, Seongnam-Si, Gyeonggi-Do 13120, Korea; \\ sesuh@gachon.ac.kr; Tel.: +82-31-750-5948
}

Received: 17 January 2020; Accepted: 4 March 2020; Published: 5 March 2020

\begin{abstract}
This study qualitatively analyzes the phenomenon of fashion everydayness as a cultural revolution in the digital space as everyday life continues to expand into digital platforms. The analysis proceeded in four perspectives based on Lefebvre's theoretical framework: the festivalization of everyday life, the artification of everyday life, the holistic stylization of everyday life, and cultural revolution as a daily practice. Instagram, the case for this study and the most popular image-centric social network, leads the digital aesthetics paradigm through creative acts that weave fashion into the daily life of the individual. The study focuses on three fashion mega-influencers whose successful careers began with blogs documenting their daily lives. The analysis showed that Instagram, as a social platform, is a creative space for sharing everyday life with its appropriation of time and space. In there, fashion visualizes the look of the everyday beyond the boundaries of time and space. In practice, it suggests a digital cultural revolution: a composite lifestyle expressive of various tastes and styles-a vital medium to inspire and sustain fashion everydayness. This has implications that the information and communication technology of the digital age created a new cultural space and that daily visualization through fashion will eventually produce sustainable cultural contents.
\end{abstract}

Keywords: cultural revolution; social media platform; Instagram; fashion everydayness; digital space and time

\section{Introduction}

Culture continues to experience tremendous changes in communication methods and information consumption as digital technology and social media develop and evolve. The mobile device has become fundamental for everyday communication even as its presentational medium rapidly shifts from text to images and videos. In turn, the concept of daily time and space has been reconstructed and reproduced, following the operating mechanism and rhythm of information and communication media from the computer and the Internet to cellphones and smartphones [1] (p. 615). From a linear and cyclical conceptualization of time, the advent of digital space reconceives time now as simultaneous, fluid, and transcendent [2] (p. 10). Digital space has claimed aesthetics as a creative space for individuals in their everyday life-the space of cultural consumption, production, and distribution in present society. In time, the idea of everyday life may also extend to virtual or augmented reality.

In sociology, everydayness is a core theme in works reconstructing the vitality, creativity, and aesthetics of everyday life in postmodern society [3]. De Certeau, for example, stressed the daily continuance of creative work in one's life for rejuvenation and transformation [4]. On the other hand, Maffesoli viewed the space of everyday life as a space of personal emotional creation and presented the digital space as a domain of everydayness revelatory of the fundamental power that constitutes society in the digital age [5]. 
Fashion has been recently attracting attention as a daily phenomenon that projects our everyday lives on a digital platform. Posts from diverse, influential fashion Instagrammers and YouTubers are projected as lifestyles and values of the millennial generation, accelerating the digital renovation of the fashion system. Leading fashion theorists Agnés Rocamora, Eugenie Shinkle, and Reina Lewis discuss similar themes in their works, focusing on fashion images and personal style of influencers in the blogosphere as new fashion media. Shinkle [6] (p. 1) emphasized that digital image and fashion interactives, wherein users can select and control via a computer interface, now seem ready to replace the still photograph as a key media form of fashion.

Similarly, Rocamora [7] (p. 1) stated that fashion blogs have become key players in the field of fashion, evident among personal fashion blogs documenting the blogger owner's style. The medium represents a significant space that encourages individual identity while establishing itself as a central form of fashion blogging. In the era of new media, personal styles emerge from fashion recipients who create their own image by transforming and combining fashion information through the representative social media [8] (p. 2). Rocamora also consistently discusses the rise of the fashion blogosphere and the impact of new technologies on fashion [9-11]. Additionally, Lewis said that the fashion blog is an open network that provides an opportunity to introduce a variety of global and local fashion [12]. Luis, Ana-Isabel, and Ubaldo [13] discussed the critical influence of the rise of Instagram as the fastest-growing social network in beauty and fashion brands. Wang, Ahmed, Deng, and Wang [14] examined the overall performance achievement of social media marketing, even in Bangladesh.

The appropriation of time and space on digital platforms-blogging in this case-follows Henri Lefebvre's concept of cultural revolution in which innovation and change are pursued through everyday creative practice. The digital platform has thus become a new place of digital everydayness, and Lefebvre's vision of overcoming alienation in everyday life through appropriation as the identification of self the value of festivals and play, and as a resurgence of style and artwork, is well suited to studying the everydayness of fashion in social media.

Within these contexts, this study qualitatively analyzed the role of fashion in visualizing everyday life in social media and the concordant influence of digital space on the digital paradigm of fashion. The focus is on Instagram as an image-driven digital media where people visually represent everyday moments and as a platform for representing individual styles through fashion-centric images. With the intent of following the trajectory of how a casual Instagrammer transition to a mega-fashion influencer, Tavi Gevinson (@tavitulle), Susanna Lau (@susiebubble), and Chiara Ferragni's (@chiaraferragni) blogs were selected for the analyses. The selected blogs were analyzed following four perspectives, based on Lefebvre's concepts: the festivalization everyday life; the artification of everyday life; the holistic stylization of everyday life; and cultural revolution as a daily practice.

\section{Literature Review}

\subsection{Fashion in Everyday Life}

Recently, the subject of everyday life has become more critical in fashion studies. According to Buckley and Clark [15]:

"Fashion and everyday life are somewhat multivalent terms. Everyday life can refer to both experience and synchronicity. The everyday experience is in its typical form today, as it was yesterday and will be tomorrow; what constitutes everyday life changes according to the time and place. Fashion was integral to everyday life in the 20th century, and its impact grew as the century progressed. As a visual spectacle and material object, fashion offered the potential for the extraordinary to occur in the context of the everyday, thus enabling transformations in appearance and identities". [15] (p. 1)

In conjunction, Lefebvre and Levich [16] considered fashion, along with food and housing, as "essential for everyday life, as constituting autonomous subsystems and representing a diversity" [16] (p. 8). 
The everyday is a "set of functions that connect and join together systems that might appear to be distinct" [16] (p. 9). Linked together, it results in the concept of "style," including functions and structures as integral parts of its form [16] (p. 8). If one can consider the relationship between fashion and everyday aesthetics based on the content the former produces, fashion, "in everyday mode," could be interpreted as a configuration of lifestyle; fashion-as-lifestyle can be considered as the emblem of this new state of things" [17] (p. 241).

Ash and Wilson [18] recognized the diverse ways in which fashion intersects with everyday life, and identified fashion as one of the most immediate and everyday cultural manifestations. In agreement, Buckley and Clark [15] consider fashion to be embedded and contingent in the practices of people's daily lives, both a personal expression of everyday life and a sociocultural phenomenon; everyday clothes routinely worn by people reveal an ongoing engagement with fashion on a scale from extraordinary to ordinary - either of which can be indicative of the everyday [15] (p. 7). There is also the essential contradiction and tension in daily life: stable and impermanent but always in a process and, therefore, imperfect [19] (p. 75). These contradictory characteristics of everyday life relate to the double-sidedness of fashion: it can be ordinary and extraordinary, routine and special, or essential and updated. We try not only to wear everyday clothes in the routine of life, but also to express self-image in our own style. We also dress in more extraordinary ways to express the everyday in special situations, such as festivals, events, and leisure activities.

Considering the trajectories of fashion in everyday life, "it is possible to explore the fault lines or intersections of ordinary fashion with ongoing lives" [15] (p. 3). When a contemporary fashion trajectory can be traced over the last century in the catwalk, the magazine, the boutique, the department store, and the designer, fashion is present in the distinct, superior, specialized, structured activities [15] (p. 9). When tracing fashion in everyday life, the everyday may be obvious: readily exposed by rummaging through diaries, letters, photographs, and other such alternative sources instead of looking at government records as Highmore mentioned [20] (p. 1). As our living space has expanded to the digital space, everyday life and fashion are now traceable via social media platforms. Therefore, fashion, everyday life, and the social media platform need to be discussed more in a syntagmatic analysis.

\subsection{Digital Everydayness as Cultural Revolution}

\subsubsection{The Concept of Cultural Revolution}

Lefebvre [21] asserted the necessity of cultural revolution in 20th-century society to create a holistic lifestyle through everyday practice. Appropriation as a key concept of cultural revolution is crucial to overcoming neglected daily routines; it refers to "the management of the body, desire, and time without reliance on external bodies—an appropriate person is not alienated and is self-possessed" [21] (p. 39). Appropriation as creative action is to derive potential from ordinary everyday life; as such, the products of nature and the social turn into goods [21] (p. 77). "Appropriating social and natural beings" is essential to human life and is opposed to the capitalist social order dominated by exchange values [10] (p. 38).

"Everyday artwork" is a cultural revolution that refers to the creation of culture as a lifestyle [21]. In other words, Lefebvre's cultural revolution is the reclamation of style and work created by one's whole being [2] (p. 3). Instagram expresses the various daily desires through fashion-a visual medium. Influencers form visually unique identities through their fashion tastes and lifestyles, which means establishing the holistic stylization of everyday life through one's fashion image.

\subsubsection{The appropriation of Time and Space in Digital Space}

According to Lefebvre, the "appropriation of time has its own character. It does not come as calculated; it comes when an activity brings fullness. These activities include aspects of self-creation and talent to achieve harmony with oneself" [22] (p. 208-209). In the context of the appropriation of time, he emphasized the need to restore the "rhythm of me" through a rhythm analysis of daily life [22] 
(p. 20). Lefebvre also defined an appropriated space as "a space modified to realize the needs and potential of a group" [23] (p. 58) and emphasized the need to recognize space as a social medium of life open to ever-changing lives and numerous possibilities. De Certeau perceives social space as variable according to human creativity and practice [2]. Aesthetics in spatiality are linked to the aesthetics of everyday life. These aesthetic values are no longer carried out by privileged or professional artists but are permeated into the daily life and space of ordinary people to improve the quality of life in general [24].

The greatest change that had emerged in the advent of this digital era is cyberspace; social media platforms as virtual and integrated spaces of everyday life in particular. As a lifestyle, fashion appropriates the time and space of everyday life in a digital space and generates its own value. Fashion has been also democratized in the digital space, no longer owned by privileged groups as how high fashion was exclusively accessible for them. Social media platforms opened a way to various kinds of fashion to the public, encouraging anyone to express and share personal fashion in everyday life in public.

As social networks evolved into media platforms, its position and influence in the cultural ecosystem increased [25]. According to the 2018 Netizen Profile Research Report of NAS Media [26], Instagram, which freely presents uploaded pictures with an intuitive search engine that uses hashtags, had the highest utilization rate of that year. Naturally, the formed trend is that users express and boast of their daily life on Instagram [27].

\subsubsection{Digital Everydayness and Fashion}

Lefebvre and Levich [16] wrote:

"The everyday is situated at the intersection of two modes of repetition: the cyclical, which dominates in nature, and the linear, which dominates in processes known as rational. The days follow one after another and resemble one another, and yet here lies the contradiction at the heart of everydayness: everything changes, but the change is programmed". [16] (p. 10)

The organizing principle of spatial composition in 20th-century industrial society was the control of human beings according to unilinear time. The cycle of time and space was uniformly divided by night and day, labor and relaxation, and so on [1,28] (pp. 614-615). Time in the digital age, however, is current, transcendent, and immediate. In such an age, cyberspace embodies everything imaginable, while physical space provides a safe basis for reality and materiality [29].

As digital society advanced, the convergence of these different sections of everyday life are given representation from the differentiation and convergence of the physical and cyberspaces, the dissolution of boundaries between the public and private, and the collapse of the time-space cycle of labor and leisure that governed the industrial society. Now and wherever, citizens enjoy a new spatial system that connects everyone in "my own space without space"; it also began a possible future where one could live beyond the traditional boundaries of time [30]. Especially in social media, people are always connected in real time and transcend the boundaries of public and private realms as well as work and leisure. As social media platforms expand into everyday time and space, fashion also visualizes this phenomenon on the social platform every day.

Kawamura [31] noted that the impact of technology is evident in every interactive sphere of our lives, including how individuals, particularly the youth, socially interact within fashion communities. Rocamora [7] (p. 1) said that personal fashion blogs have established itself as a central form of fashion blogging by posting photos of bloggers documenting their style in everyday life. Rocamora $[9,10]$ also discuss the rise of the fashion blogosphere and the impact of new technologies on the mediation of fashion. She showed the relevance of the concept of the mediatization for understanding the contemporary field of fashion and its relation to digital media, in fashion production and retail. 
The mediatization of fashion reaches out to ordinary practices of the self, a mediatized self through the use of digital cameras, the same as wearing cosmetics [11].

This study proposes a conceptual model of fashion everydayness on the social media platform, particularly the Instagram case, as a creative cultural revolution through the appropriation of time and space in the digital space (See Figure 1).

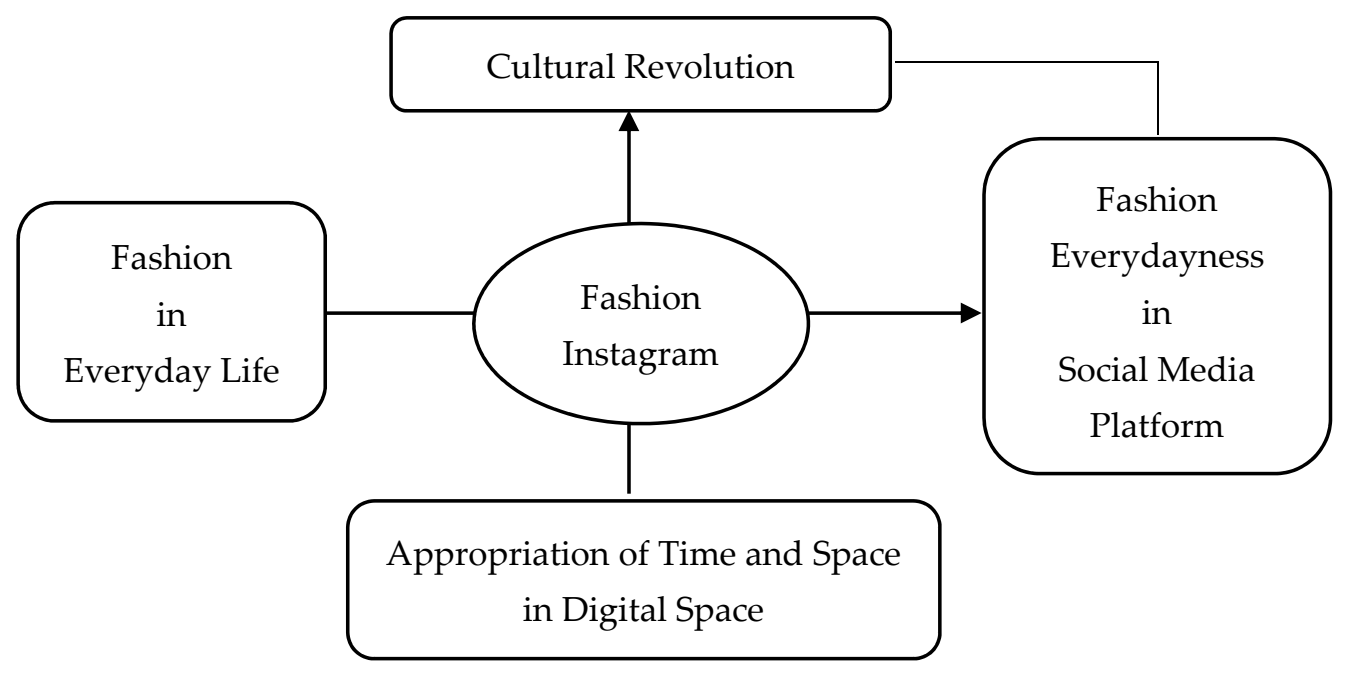

Figure 1. Research Model.

\section{Methodology}

Ormston, R., Spencer, L., Barnard, M., and Snape, D. [32] discussed the major characteristics of qualitative research and the importance of understanding key philosophical issues in the development of social research. They focus the use of the following: non-standard and adaptable data generation that are sensitive to social context, analysis that retains complexity and nuance and respects the uniqueness of each participant or case, and most especially, qualitative research that includes detailed descriptions of the phenomena being researched, grounded in the perspectives and accounts of participants (p. 4).

This study qualitatively analyzed the role of fashion in visualizing everyday life on social media and the concordant influence of digital space on the digital paradigm of fashion. First, the sociological discourse on daily life and previous studies on fashion and everyday life are examined, and the concept of the appropriation of time and space, digital everydayness, and fashion phenomena based on Lefebvre's theory of everyday life are discussed. The paradigm of the cultural revolution established in social media platforms was derived from four concepts: the festivalization of everyday life; the artification of everyday life; the holistic stylization of everyday life; and cultural revolution as a daily practice. These four perspectives are the framework of analysis for the Instagram case study selected.

Jensen [33] discussed that qualitative research methods that combine theoretical and practical approaches as alternatives to the methodological limitations and criticisms of questionnaire-based quantitative research in the field of media research. Kozinets [34,35] introduced the discipline of netnography as a qualitative research — the conduct of ethnography over the internet-a method specifically designed to study cultures and communities online. Miller and Slater [36] defined Netnography as a combination of the internet and ethnography. Netnography is carried out in parallel with a variety of methodologies, including participatory observation, interviews, discourse analysis, archive analysis, and field trips. In this paper, the case study was conducted by analyzing the fashion images and contents of influencers on Instagram's social media, based on the analysis of archives in the methodology of netography.

In Visual Methodologies, Rose [37] highlights the influence of images given its meaning and construction (p.32). Martínez, Llodrà, and Jiménez [38] highlight the impact of social media on target image formation. This study treated Instagram—or the site of image according to Rose—as the most 
representative image centric form of social media that expresses various aspects of everyday life in the digital era. The focus is on Instagram as an image-driven digital media platform where people visually represent everyday moments and as a conduit for representing individual styles through fashion-centric images. With the intent of following the trajectory of how a casual Instagrammer transitions to a mega-fashion influencer, Tavi Gevinson (@tavitulle), Susanna Lau (@susiebubble), and Chiara Ferragni's (@chiaraferragni) Instagrams were selected for the analyses.

The data were collected from 14,277 images uploaded on the three Instagram accounts between January 2013 and December 2019. Four fashion experts (including two professors and two PhD students) reviewed fashion images based on the research framework set up from the theoretical background, collecting 450 images, with random 20-30 images of each Instagrammer from each year. In the process of collecting relevant images, images introducing designer collections, publicizing events, and featuring products or places without Instagrammers themselves were excluded. Once similar images are clustered by topic, the one most representative of that topic was selected. These 450 images were then subjected to an integrated secondary assessment and were categorized into four groups then their images, content, hashtags, and comments in conversation were reviewed based on the detailed context of the analytical framework. Subsequently, the 18 representative images that are specifically analyzed in this study are those that most clearly exhibited fashion everydayness in the four perspective of cultural revolution on social media.

This study takes a conceptual and qualitative research methodology to discuss fashion everydayness on the social media platform with Instagram case studies as the digital cultural revolution. The study also focused on three influencers globally recognized by personal fashion practices on the Instagrams and establishing their own aesthetic identity (See Figure 2).

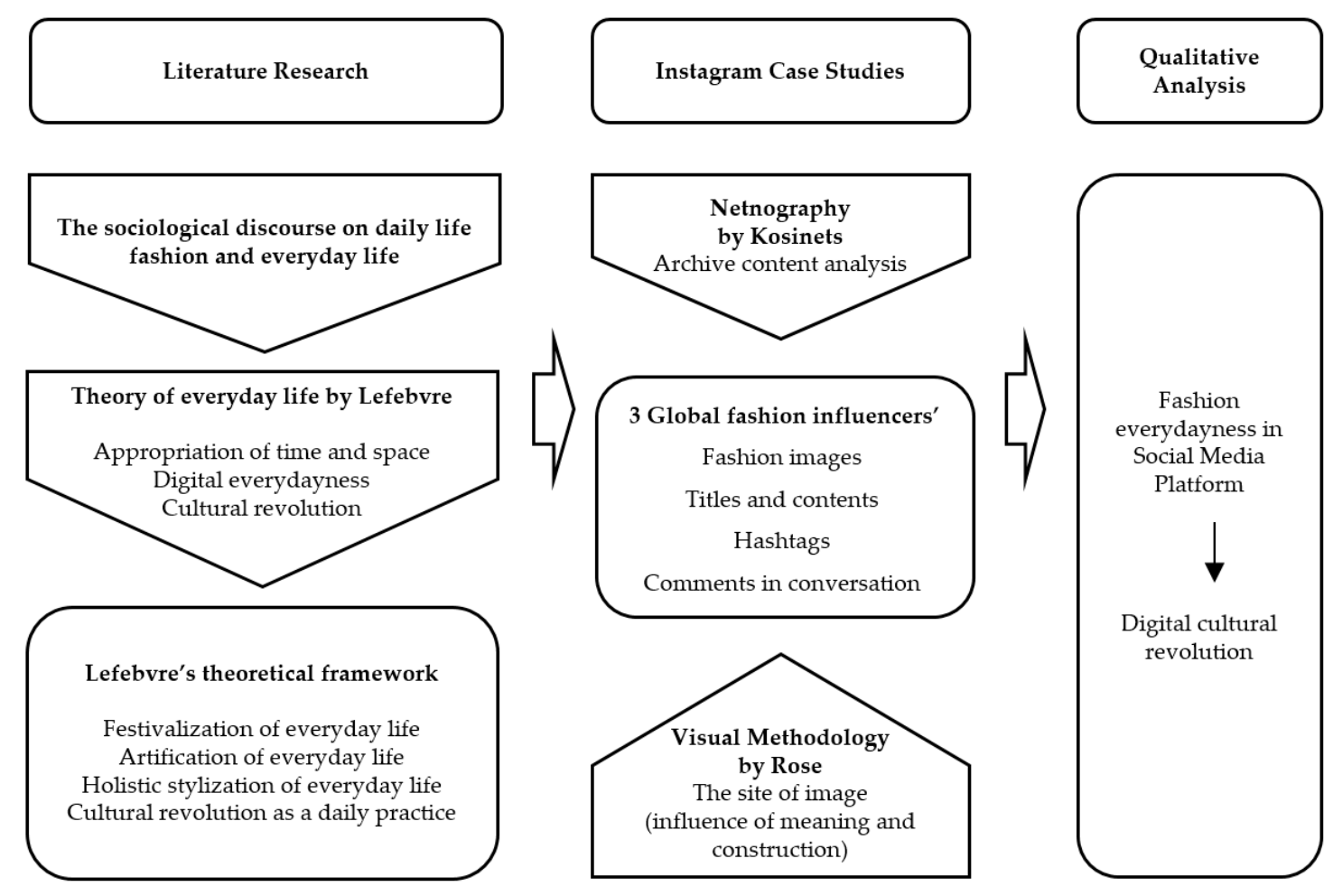

Figure 2. Research Methodology Model.

\section{Results and Discussion: Fashion Everydayness in Selected Instagrams}

\subsection{The Festivalization of Everyday Life}

According to Lefebvre [39] (p. xxviii), a festival, like a revolution, marks both a break in everyday life and a rehabilitation of the everyday. He also emphasized the importance of "leisure activities" 
and "work-leisure unity" in everyday life [39] (p. 29). Leisure as a festival is an energy for creative production outside the framework of spatial organization, as well as the rationality and efficiency of capitalist time and economic production. Through this festival, Lefebvre pursued the practice of transforming the everyday, producing a new space in the day-to-day [40].

Similarly, Instagrammers transform their daily lives into festivals by dissipating the boundary between work and life. Ferragni and Fedez's post at Kudadoo Maldives Private Island (Figure 3) demonstrates the blurred boundaries between the public and the private as well as work and leisure. Ferragni may be on private vacation, but she is also promoting her label's new swimsuit collection. In this way, they present a certain fashion style and subsequently promote related products. Special occasions also become an opportunity, such as Ferragni's post of her family donning Batman costumes for Halloween (Figure 4). On Instagram, the festivalization of everyday life shows that personal spaces and daily activities can become special and extraordinary, representing play.

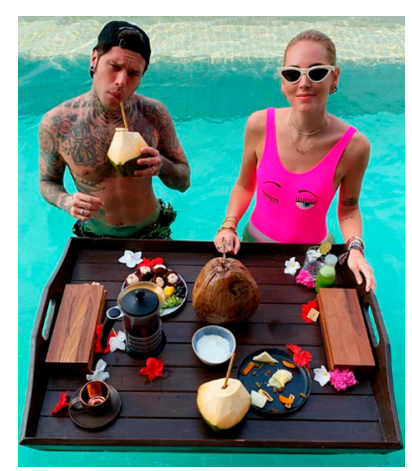

Figure 3. Ferragni and Fedez at Kudadoo Maldives Private Island. Reference: https://www.instagram. com/p/BsIFbMXBI4h/ (accessed on 2 March 2019).

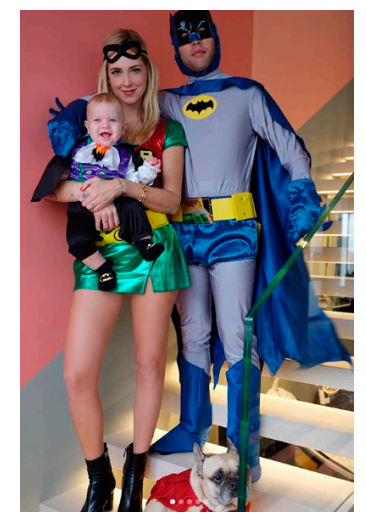

Figure 4. Ferragni's family in Batman costume. Reference: https://www.instagram.com/p/ BpmIye7FqFn/ (accessed on 2 March 2019).

De Certeau proposed everyday life as a set of practices that, although established, offer the potential for creativity [4]. As for making do with this everyday culture, people have also been making with it: transforming and inventing by appropriating and redeploying [13] (p. 9). The duality of fashion is to express everyday life as a festivity, a means of releasing latent desires onto the ordinary. In the digital space, fashion transforms everyday life in this way: a cultural revolution of art and style, play and festival.

The social platform represents the festival of everyday life in expanded time and space, "digital space fluidity" [41] that allows users to extend daily horizons beyond time and space in a tight network. This is particularly seen from influencers' Instagram posts before their commercial success. Instagrammers commonly start representing everyday fashion in intimate spaces, like their own house, and be recognized by friends around. 
As the everyday space of "house" appeared as the main location for Instagram shoots, spaces that used to be regarded as very private-bedrooms, toilets, kitchens, decks, and yards—are transformed into special studios. In Figure 5, a young Tavi Gevinson photographed herself on the deck of her house. This particular photo is among the first ones she posted when she started blogging at the age of 11. The use of kitchens and dining rooms as an aesthetic space is also prevalent in Instagram. Here, in Figure 6, Lau is drinking coffee in a very café-like dining area. The bathroom is also always one of the popular spaces presenting one's self-image fashionably. In Figure 7, Gevinson calls her reflected image "pants and shower curtain and life."

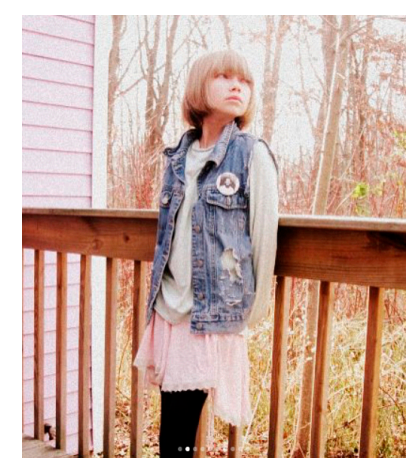

Figure 5. Eleven-year-old Gevinson on a house deck (second photo in the slideshow). Reference: https://www.instagram.com/p/BSWSd6MBIWr/ (accessed on 15 March 2019).

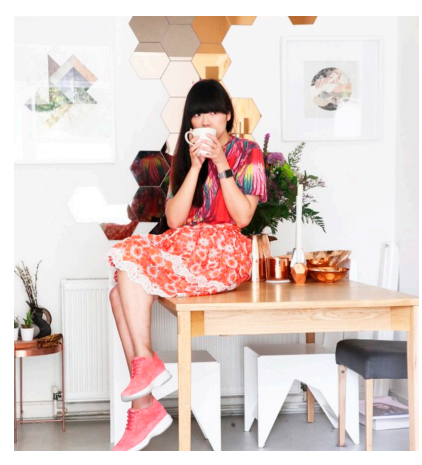

Figure 6. Lau in a dining room. Reference: https://www.instagram.com/p/2yAJ7PKar3/ (assessed on 27 March 2019).

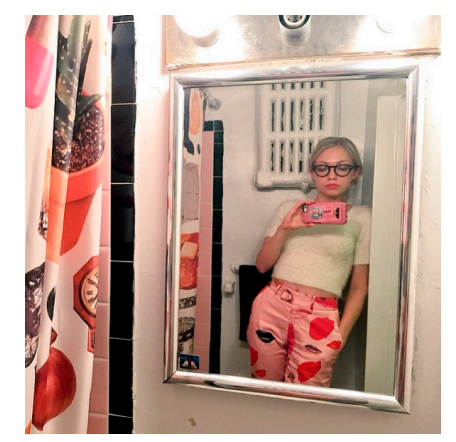

Figure 7. Gevinson in a toilet. Reference: https:/www.instagram.com/p/4GndyBG_TC/ (accessed on 15 March 2019).

Instagrammers set the latest trends of eating and drinking alone in a relaxed and stylish manner. Such posts seemingly encourage followers to admire and enjoy their own leisure time. The same can be said with maintaining fashionable appearances in otherwise common circumstances such as walking a dog, grocery shopping, or going to school (Figure 8). This is because the moments captured 
on Instagram, as a routine of everyday life, can be seen as a "festivalized" moment. In other words, Instagram provides a space to transform the everyday ordinary into the extraordinary, even into one's ideal image.

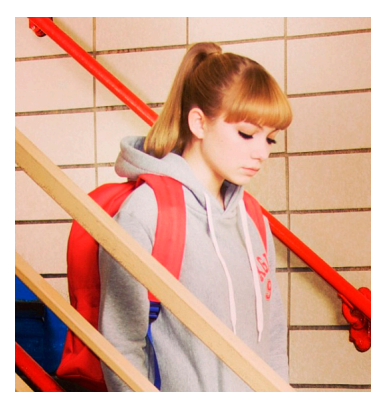

Figure 8. Gevinson going to school. Reference: https://www.instagram.com/p/Ub078am_aY/ (accessed on 15 March 2019).

Such posts can also be a means of unearthing the alienated parts of everyday life. Bloggers Lau and Ferragni showed that fashion can be produced, even in situations where women's fashion is alienated, such as in pregnancy and child care. In Figure 9, Ferragni dons a casual and funky look: mini satin dress, a denim trucker, polka-dot mesh stockings, and a pair of black Dr. Martens. Her stylish look is a stark contrast with the typecast accorded to pregnant women. Lau's post of herself wearing a metallic, sheer pink top and sunglasses as she breastfeeds her child (Figure 10) echoes that of Ferragni's. Even during times when fashion may be timid and passive, both posts celebrate the natural changes in female's bodies. In this way, fashion images expressed on the social platform emit everyday desire from a preconceived routine, whether that desire is beauty for the sake of it, or a festival and a restorative for everyday energy to penetrate a pre-given reality.

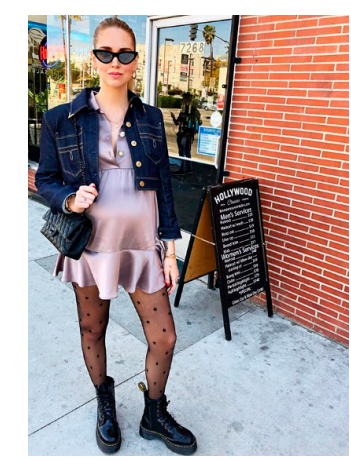

Figure 9. A pregnant Ferragni. Reference: https://www.instagram.com/p/BgCOGQMDE-o/ (accessed on 8 March 2019).

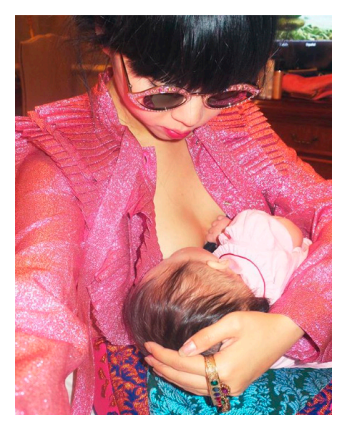

Figure 10. Lau breastfeeding. Reference: https://www.instagram.com/p/BYlmSZUlGgw/ (accessed on 27 March 2019). 


\subsection{The Artification of Everyday Life}

In Lefebvre's theory of cultural revolution [21], the full reconstruction of concepts such as work, creation, freedom, appropriation, style, value, and human existence are necessary [19] (p. 348). His posit, "Let the everyday become a work," no longer refers to an artistic object. Instead, it is to know and understand oneself, to set their own conditions and express them as such with their bodies, desires, time, and spaces. This is artification as appropriation: the act of becoming one's own artwork [21] (p. 355-356).

Aesthetics in spatiality are linked to the aesthetics of everyday life. Aestheticizing the emotional circulation of everyday humans through reinforcement of the aesthetic function of the everyday spatial environment, means liberating the lifestyle of the masses with flexibility, diversity, and solidarity. However, these aesthetic values are no longer carried out by privileged or professional artists but are permeated into the daily life and space of ordinary people to improve the quality of life in general [24]. In the case of Instagram, it is a medium accessible to everyone but begins in private. The general public can trace the lifestyle of an influencer as if it were a diary, capturing their past, present, and future via visual images and videos.

In Figure 11, Lau is seen lying down on a handmade boucherouite rug, wearing a waterfall knit by JW Anderson that matches the rug's design on her Instagram (@susiebubble). The rug and her knit artistically meld into each other, making Lau look as if she were part of a single piece of artwork itself. In a similar manner, Gevinson's post of herself as a Cabbage Patch Kid with creepy doll-like lips painted over her own and posing under some plants in her garden (Figure 12), can be taken as an example of how one artificate themselves. In this example, artification occurs with Gevinson pretending to be a doll, photographed in a space depicting everyday life.

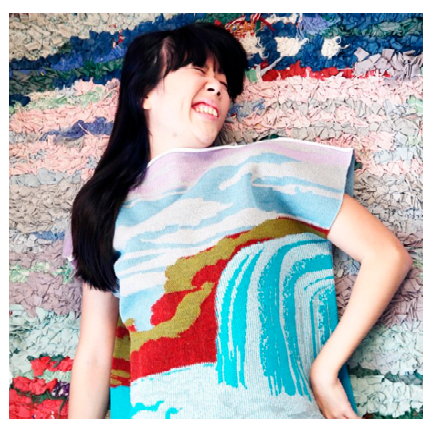

Figure 11. Lau lying down on a boucherouite rug. Reference: https://www.instagram.com/p/ xKpg3HKahd/ (accessed on 27 March 2019).

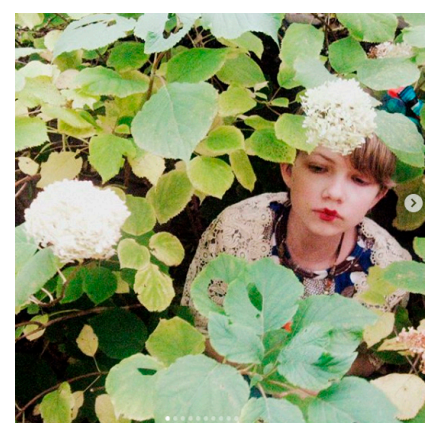

Figure 12. Gevinson pretending to be a Cabbage Patch Kid (first photo in slideshow). Reference: https://www.instagram.com/p/BSWSd6MBIWr/ (accessed on 15 March 2019).

Instagrammers also utilize multiple digital and visual techniques to express themselves; they are not limited to material resources in digital space. Fashion images on Instagram make everyday life look like art, expressing it as an imaginary or virtual image that transcends everyday life. For instance, 
Figure 13 shows Lau in a pale pink dress with a haze of pink clouds behind her. In her post, she captioned it as "A morning of milk vom and poonami means I've momentarily escaped into a haze of pink clouds." Gevinson has a similar post (Figure 14) of herself in a dress with a floating UFO print. Here, Gevinson captions the post as "being a prepubescent alien." This is backed by what Suh and Kim [8] (p. 134) discussed that dreams and imagination are inspirations for the imaginary self, and that social media is a virtual space where it can be realized. And advanced digital technologies, such as visual literacy, contribute to the artistic creation of Instagram's visual images.

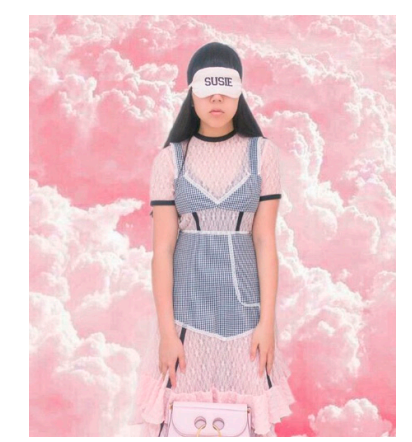

Figure 13. Lau with pink clouds as a backdrop. Reference: https://www.instagram.com/p/ BRqkRHblH9i/ (accessed on 27 March 2019).

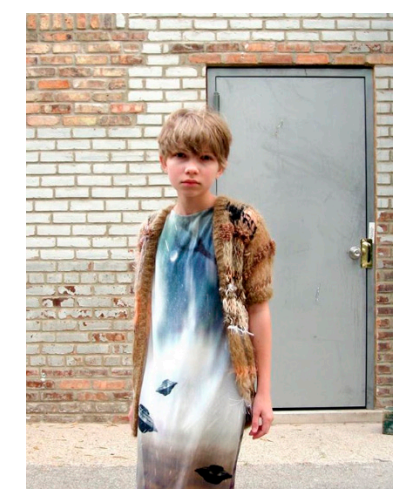

Figure 14. Gevinson pretending a prepubescent alien. Reference: https://www.instagram.com/p/ BM72ELtDHod/ (accessed on 15 March 2019).

\subsection{The Holistic Stylization of Everyday Life}

For Lefebvre, cultural revolution refers to the transformation of the outside world as well as everyday life to create a new, holistic lifestyle [42]. He emphasized the symbolic value of the "whole" as a complex, linking from the smallest tool to the greatest works of art and learning [21] (p. 8). "Everyday artwork" is a cultural revolution that refers to the creation of culture as a lifestyle [21]. In other words, Lefebvre's cultural revolution is the reclamation of style and work created by one's whole being [2] (p. 3). Instagram expresses the various daily desires through fashion-a visual medium. Influencers form visually unique identities through their fashion tastes and lifestyles. This means establishing the holistic stylization of everyday life through one's fashion image.

In Figure 15, Lau's signature bangs and top-knot, including her clutch printed with her name (SUSIE!), define her style identity. Her other posts often depict such identity; for example, Figure 16 is a collage of Lau's unique street style as a global fashion influencer. Ferragni became known for her signature motif "a winking eye with long lashes," and even launched a whole collection of a shoe and bag label featuring such design (Figure 17). She similarly showcases her jet-setter lifestyle as a global influencer (Figure 18). Figure 19 shows Gevinson updating her style in this dressing room post, as most influencers do on a daily basis. Her published collection of articles, interviews, photo 
editorials, and illustrations (Figure 20) from the now-closed online magazine, Rookie, can be seen as the penultimate example of the holistic stylization of everyday life. Both style book and magazine depict Gevinson's signature style but recreated with the purpose of influencing the lifestyle of the teenager.

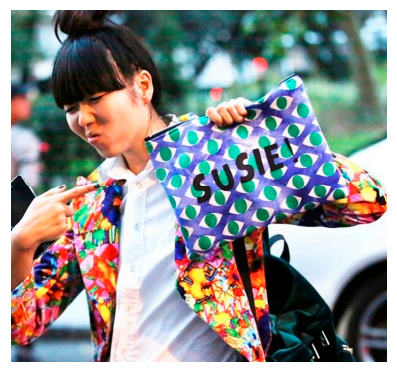

Figure 15. Lau's signature bangs and top-knot hair. Reference: https://www.instagram.com/p/ BTj1JC61mF9/ (accessed on 27 March 2019).

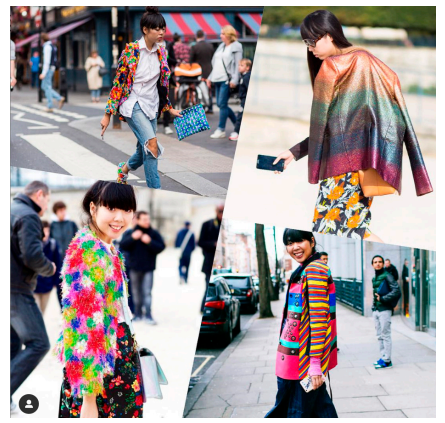

Figure 16. Lau's unique street style. Reference: https://www.instagram.com/p/6W9nBhqak2/ (accessed on 27 December 2019).

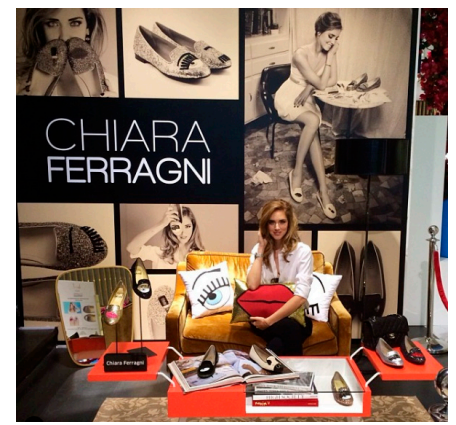

Figure 17. Ferragni collection space at Dubai mall Reference: https://www.instagram.com/p/nXe3JyD4B/ (accessed on 13 December 2019).

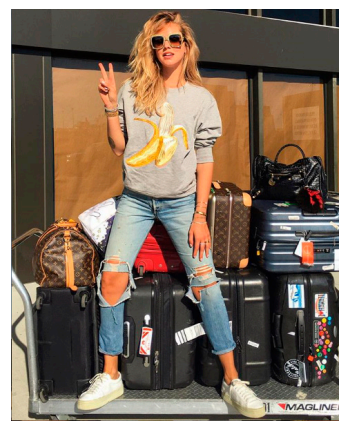

Figure 18. Ferragni showing how she travels in style. Reference: https://www.instagram.com/p/ BKbhHnYAYWr/ (accessed on 13 December 2019). 


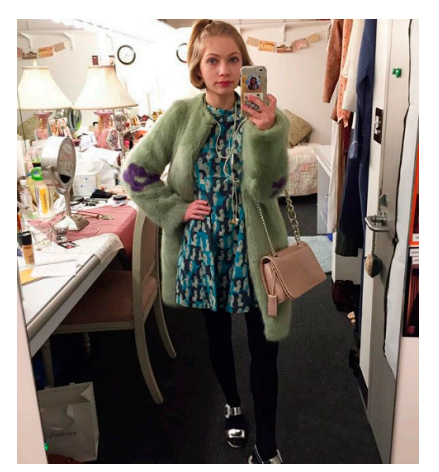

Figure 19. Gevinson's style update from the dressing room. Reference: https://www.instagram.com/p/ BMZU5DGjEGt/ (accessed on 15 December 2019).

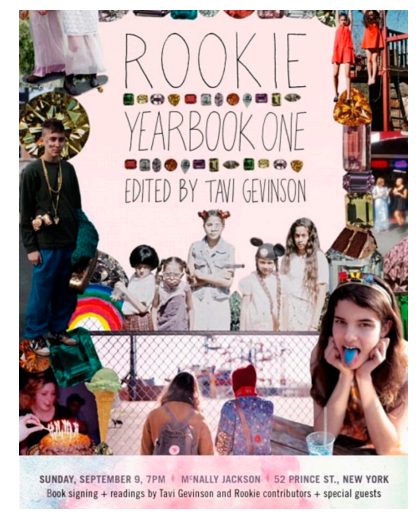

Figure 20. Gevinson's article and photo collection, "Rookie Yearbook One." Reference: https://www. instagram.com/p/PQQXR0m_Xk/ (accessed on 20 November 2019).

The style and identity created on social media set the holistic stylization of everyday life, and maximize the product value of fashion because of high viewership and how these viewers connect to the celebrities. As the public and experts recognize the fashion styles of influencers, the number of followers increases and social connections expand. The number of followers determines the net worth of Instagrammers: as their net worth increases, so does the value of their promoted products. Instagram presents the opportunity to become influencers by forming unique, trusted identities based on the differentiated content of their lives to connect with their followers. Influencers will continue to showcase their diverse creations and collaborations to the public based on this social connection. In Instagram, the process of establishing individual taste as style maximizes the use and exchange value of promoted goods through social connectivity.

\subsection{Cultural Revolution as Daily Practice}

Lefebvre [21] asserted the necessity of the cultural revolution in 20th-century society to recreate a style, revive festivities, and collect scattered remnants of culture in everyday transformation. Interest and criticism in daily life have become important goals of the cultural revolution to rebuild the value of past works and to restore time as the best asset to life [21] (p. 352).

The social media platform is being influential on the recovery of meaning and value of everyday life. The social media platform presents a new time-space ecosystem with time's free movement, in which past, present, and future give the impression of coexisting in digital space, bringing various changes in daily rhythm. On a social platform, one can communicate with people at different time zones and share various moments of their daily life and record these as meaningful moments.

The social platform visualizes the small and repetitive routines that have been alienated through social connections, subsequently building an ecosystem that allows the unspecified majority to share 
beyond space and time. Fashion plays a very special role in visualizing the digital daily life in such a media environment. Image-driven social platforms like Instagram have become a springboard for many fashion non-experts and the general from diverse backgrounds public become global fashion influencers: Ferragni was a law student in Italy and Gevinson was 11 years old when she began her blog in Chicago, subsequently earning a reputation as America's youngest fashion blogger. Lau, also, was a British-born Chinese magazine editor based in London.

As an image-driven social media platform, Instagram became the hub of personalized taste and fashion as an everyday lifestyle, securing a playful space and providing real-time updates [43]. This makes Instagram the leading digital paradigm of fashion through creative activities that mediate fashion in an individual's daily life. Through fashion images on Instagram, the process of expressing daily life as a kind of festival and work of art, and gaining one's identity through an individualized style can be considered the practice of the cultural revolution that reflects digital everydayness. This cultural revolution was confirmed through creative practice in a new ecosystem appropriated to Instagram's time and space. Just as Lefebvre emphasized cultural revolution as a way of overcoming the marginalization of life by 20th-century capitalism, fashion as cultural revolution refers to the holistic stylization of life through creative presentation of various aspects of everyday life in the digital space.

\section{Conclusions}

\subsection{Theoretical Contributions}

Currently Fashion has been attracting attention as a daily phenomenon that projects our everyday lives on a digital platform. Leading fashion theorists Agnés Rocamora, Eugenie Shinkle, and Reina Lewis have discussed fashion images and the personal style of influencers as self-presentation and identity in the blogosphere as new fashion media. This study contributes to the literature of social media influence on fashion through the conceptual and qualitative approach by focusing how digital space-time in social media represents a fashion image and the actual fashion lifestyle changes.

The study's results are meaningful in terms of the research on social media platforms, fashion Instagram in particular, as a new sustainable cultural space for expressing daily life as well as a lifestyle. As shown in the selected Instagram accounts, the digital everydayness of fashion is visualized in social media platforms: an assertion that blogging can be the cultural revolution of everyday life. Lefebvre emphasized the need to have practical goals for cultural revolution to transform everyday life and how they form a counter-cultural space in the daily space. This revolution is achieved through the creative practices of individuals in a new ecosystem observing a different time-space. The social media platform is an ecosystem that can share diverse aspects of everyday life beyond physical space and time through social connection. This is the case with Instagram, which has become a cornerstone for many fashion non-experts to turn into global fashion influencers.

In addition, it is meaningful to clarify that fashion Instagram acts as a new time-space ecosystem that can be seen as festivals of everyday life. They act as mediators of latent desires-the banal, repetition, and alienation. It is very similar to the dual nature of fashion that simultaneously pursues ordinariness/extraordinariness and routine/change. This means that while clothes are a basic need, fashion allows people to express everyday life as special and extraordinary, a festival in the routine of everyday. On Instagram, such festivalization becomes a means to reenergize oneself by capturing the ordinary and monotonous and transforming them into special moments through fashion blog posts. Additionally, the aesthetically spatial function of Instagram made the artification of everyday life possible. Influencers have commonly used visual digital literacy on Instagram to make everyday moments look like works of art, or post virtual images that go beyond the everyday and, in some cases, reality itself.

Furthermore, this study presents the meaningful conclusion that fashion practice on Instagram establishes a holistic stylization of everyday life as a cultural revolution. This is made possible by the process in which non-professionals create their own style through years of daily creative practice. 
Influencers have commonly used visual diaries as a work of the self. When this appropriation of time and space on Instagram is fully realized, social platform users become influential as social beings. The transformation of the everyday aspects of digital space and time into festivals and works of art in fashion confirms that the social growth of Instagrammers ultimately maximizes the value of fashion products.

This study emphasizes that with social platforms, the creative activity of everyday life therefore becomes equated with a cultural revolution: the process of establishing and recording the visible identity of the changing lifestyle. This study also suggests that in the digital environment, the role of fashion should be considered as a cultural revolution in everyday life that creates authentic value through a transformation of the routines of daily living into festivals and pieces of art instead of a culling of desire. This has implications that the information and communication technology of the digital age created a new cultural space and that the daily visualization through fashion will eventually produce sustainable cultural contents.

\subsection{Practical Implications}

This study mainly helps to understand the characteristics of social media use of fashion consumers in the technology media environment of the digital culture age. The case study of the global fashion influencer also helps to understand the potential needs and fashion attitudes of fashion consumers in the digital lifestyle. This is because fashion influence as a trend leader has a big impact on the public and industry in their attitudes toward clothing as well as lifestyle. Instagram visualizes the changes in everyday life according to the changes in the concept of space and time in the digital age. It also visualizes the potential needs and behavioral changes of fashion consumers through the influencer's fashion practice. This understanding is expected to become the conceptual basis for fashion companies to utilize when they create their own brand image and style.

As another practical implication, the study presents the inspiration and direction of fashion design development by exploring the role of fashion images shared on social media platforms as a space for daily creative practice. This is because Instagram presents the opportunity to become influencers by forming unique, trusted identities based on the differentiated content of their lives to connect with their followers. Influencers will continue to showcase their diverse creations and collaborations to the public based on this social connection. The study suggests that in Instagram, the process of establishing individual taste as style maximizes the use and exchange value of promoted goods through social connectivity. Fashion companies can consider the importance of storytelling and the social connectivity of influencers to increase the value of their products, and utilize this process to promote their products more effectively.

The results of this study suggest that promoting the social media space creating fashion contents as a new sustainable cultural revolution would have practical effects. This is because the study confirms the role of fashion images in social media platforms such as Instagram by analyzing cases where fashion nonprofessionals have grown from the paradigm of the cultural revolution into a global influencer. Apprehended with Lefebvre's cultural revolution of everyday life, fashion is the creative appropriation of the present based on its dynamic relationship with daily life, extensive to the various time-spaces harbored by digital media. In the future, the space where ordinary people develop their own contents and create culture in various digital spaces including social media will continue to expand. Fashion companies should keep eyes on these media and influencers and actively apply them to their brand development and promotion.

\subsection{Limitations and Future Research}

A short range of the case study may be a limitation to contribute to a more complex vision of this cultural revolution. However, three Instagram cases selected in this study to analyze fashion images on digital social media platforms are representative global fashion influencers who play a leading role in inspiring the fashion industry and bringing style trends to consumers. They are also 
leading influential persons who have always been recognized at the forefront, from the beginning of personal fashion blogging to becoming a full-time blogger as the official profession in the fashion industry. They began to publish fashion images of personal life and space and have been acting as active professional bloggers for 10-15 years, sharing personal experiences about life cycle changes, such as boyfriends, marriage, parenting as fashion images. There are also thousands of images on each Instagram, enough for the research data, and only representative images that best exhibit the theoretical framework were selected through the fashion expert's data collection process. Thus, the study suggests that it is meaningful to focus more on this small number of influencers that are globally recognized, active to date, started blogging from the beginning of personal fashion practices on social media platforms, and have established an aesthetic identity. Future research for the validation of various global influencers on social media platforms will also continue.

The generalization of the results may be limited because the analysis was limited to the last 18 selected images. Even though, this study attempted to derive appropriate cases by fashion experts that most clearly presented fashion everydayness in the four perspective of cultural revolution on social media. In addition, this study conducts a qualitative media research methodology based on the archive analysis from netnography, which analyzes images in depth, hashtags, contents, and comments on Instagram, and focuses more on the area of mages in Rose's visual methodology, in order to convince the results. Future studies of more cases of various influencers will also contribute the generalization of the results.

Digital space and time are the core foundation for creating a new ecosystem; one that would ultimately transform lives and create new cultures in which fashion, as a cultural phenomenon, would adjust to suit it. Everyday life will be sustainable, extending to various time-spaces, such as virtual or augmented reality. As different forms of media continue to increase, offering new time-space for everyday life, the way users express themselves, communicate, and interact through fashion will also change. Therefore, it is necessary to constantly discover new media spaces where individual cultural creation takes place and to study methods and forms of fashion presentations, as well as industrial applications.

Funding: This research received no external funding.

Conflicts of Interest: The author declares no conflict of interest.

\section{References}

1. Kim, J.G.; Park, S.H. A Study on the everydayness of digital society. J. Korean Socio Assoc. 2010, 44, 611-622.

2. Shin, J.E. The decentralized structure of time-space of the everyday life. Korean Socio 2010, 44, 1-28.

3. Shin, S.W. Henri Lefebvre; Communication Books: Seoul, South Korea, 2016.

4. De Certeau, M. The Practice of Everyday Life; University of California Press: London, UK, 1984.

5. Maffesoli, M.; Tacussel, P. Notes Sur La Postmodernité: Le Lieu Fait Lien; Éditions du Félin: Paris, France, 2003.

6. Shinkle, E. Fashion's digital body: Seeing and feeling in fashion interactives. In Fashion Media: Past and Present; Bartlett, D., Cole, S., Rocamora, A., Eds.; London Bloomsbury Publishing: London, UK, 2013; pp. 175-183.

7. Rocamora, A. Personal fashion blogs: Screens and mirrors in digital self-portraits. Fashion Theory 2011, 4, 407-424. [CrossRef]

8. Suh, S.E.; Kim, M.J. Imaginary ego-image and fashion styles represented in the social media; focusing on women's personal fashion blogs. J. Korean Soc. Costume 2014, 64, 128-142. [CrossRef]

9. Rocamora, A. Hypertextuality and the fashion media: The case of fashion blogs. J. Pract 2012, 6, 92-106. [CrossRef]

10. Rocamora, A. How new are new media? The case of fashion blogs. In Fashion Media: Past and Present; Bartlett, D., Cole, S., Rocamora, A., Eds.; London Bloomsbury Publishing: London, UK, 2013; pp. 155-164.

11. Rocamora, A. Mediatization and digital media in the field of fashion. Fashion Theory 2017, 21, 505-522. [CrossRef] 
12. Lewis, R. Establishing reputation, maintaining independence: The modest fashion blogosphere. In Fashion Media: Past and Present; Bartlett, D., Cole, S., Rocamora, A., Eds.; London Bloomsbury Publishing: London, UK, 2013; pp. 165-174.

13. Luis, M.V.; Ana-Isabel, V.; Ubaldo, C. Fashion promotion on Instagram with eye tracking: Curvy girl influencers versus fashion brands in Spain and Portugal. Sustainability 2019, 11, 1-18.

14. Wang, Y.; Ahmed, S.C.; Deng, S.; Wang, H. Success of social media marketing efforts in retaining sustainable online consumers: An empirical analysis on the online fashion retail market. Sustainability 2019, 11, 3596. [CrossRef]

15. Buckley, C.; Clark, H. Fashion and Everyday Life: London and New York; Bloomsbury Academic: London, UK, 2017.

16. Lefebvre, H.; Levich, C. The everyday and everydayness. Yale Fr. Stud. 1987, 73, 7-11. [CrossRef]

17. Iannilli, G.L. How can everyday aesthetics meet fashion? Stud. Estetica 2017, 45, 229-246.

18. Ash, J.; Wilson, E. Chic. Thrills: A Fashion Reader; University of California Press: Berkeley, CA, USA, 1992.

19. Kim, D.Y. Imagination of social space and everydayness in the postmodern era. Episteme 2007, 1, 62-83.

20. Highmore, B. (Ed.) The Everyday Reader; Routledge: New York, NY, USA, 2002.

21. Lefebvre, H. La Vie Quotidienne Dans le Monde Moderne; Guiparang Publishing: Seoul, South Korea, 2005.

22. Lefebvre, H. Elements de Rythmanalyse; Galmuri: Seoul, Korea, 2013.

23. Lefebvre, H. La Production L'espace; Eco Libre: Seoul, Korea, 2011.

24. Go, G.S. Cultural politics in space: For the cultural arrangement of spatial globality. Spa Environ. 2000, 14, 80-107.

25. Lee, H.Y.; Lee, K.H.; Moon, S.H.; Kim, H.Y.; Bae, Y.; Choi, S.H. Social Media in Global Era and the Future of Digital Culture Strategy; Humanculture-arirang: Kyeonggi, Korea, 2016.

26. Nasmedia. Netizen Profile Research Report. 2018. Available online: https://www.slideshare.net/nasmedia/ 2018-nprnasmediaf (accessed on 11 December 2018).

27. Son, D.H. Instagram enthusiasm, Economychosun. 2018. Available online: http://economychosun.com/ client/news/view.php?boardName=C00\&t_num=13554\&img_ho= (accessed on 28 November 2018).

28. Kim, B.S.; Son, M.G.; Jeong, S.N. Spatial and Temporal Reconstruction of Everyday Life; The Academy of Korean Studies: Sungnam, Korea, 2004.

29. Lee, J.Y. Strategy for Entering Ubiquitous Society. Institute of Information Technology Assessment; Korea Information \& Communication Research Institute: Chungcheongbuk-do, Korea, 2005.

30. Jeong, J.H. What Will Change the World; Kyobo: Seoul, South Korea, 2012.

31. Kawamura, Y. Fashion-Ology; Bloomsbury: London, UK, 2018.

32. Ormston, R.; Spencer, L.; Barnard, M.; Snape, D. The Foundations of Qualitative Research. Qualitative Research Practice: A Guide for Social Science Students and Researchers; SAGE: Thousand Oaks, CA, USA, 2014; Volume 2, pp. 52-55.

33. Jensen, K. A Handbook of Media and Communication Research; Routledge: London, UK, 2002.

34. Kozinets, R.V. The field behind the screen: Using netnography for marketing research in online communities. J. Market. Res. 2002, 39, 61-72. [CrossRef]

35. Kozinets, R.V. Netnography: Doing ethnographic research online. Sage publications, 2010.

36. Miller, D.; Slater, D. Internet: An. Ethnographic Approach; Berg Publishers: Oxford, UK, 2000.

37. Rose, G. Visual Methodologies: An Introduction to Researching with Visual Materials; SAGE: Thousand Oaks, CA, USA, 2016.

38. Martínez, M.D.; Llodrà, I.; Jiménez, A.I. Social media as information sources and their influence on the destination image: Opportunities for sustainability perception. In Managing Sustainable Tourism Resources; Batabyal, D., Ed.; IGI Global: Hershey, PA, USA, 2018; pp. 265-283. ISBN 9781522557722.

39. Lefebvre, H. Critique of Everyday Life; Verso: NY, New York, USA, 1991.

40. Kim, N.J. Dreaming of space of difference: Space production and practice. Space Soc. 2000, 14, 63-78.

41. Featherstone, M.; Burrows, R. (Eds.) Cyberspace/Cyberbodies/Cyberpunk: Cultural of Technological Embodiment; SAGE: Thousand Oaks, CA, USA, 1995. 
42. Kang, S.T. Comparative study of theories of everyday life. Korean Socio 1994, 28, 85-118.

43. Suh, S.E. Digital fashion image aura represented in the Burberry Instagram. J. Korean Soc. Costume 2017, 67, 115-132. [CrossRef] 